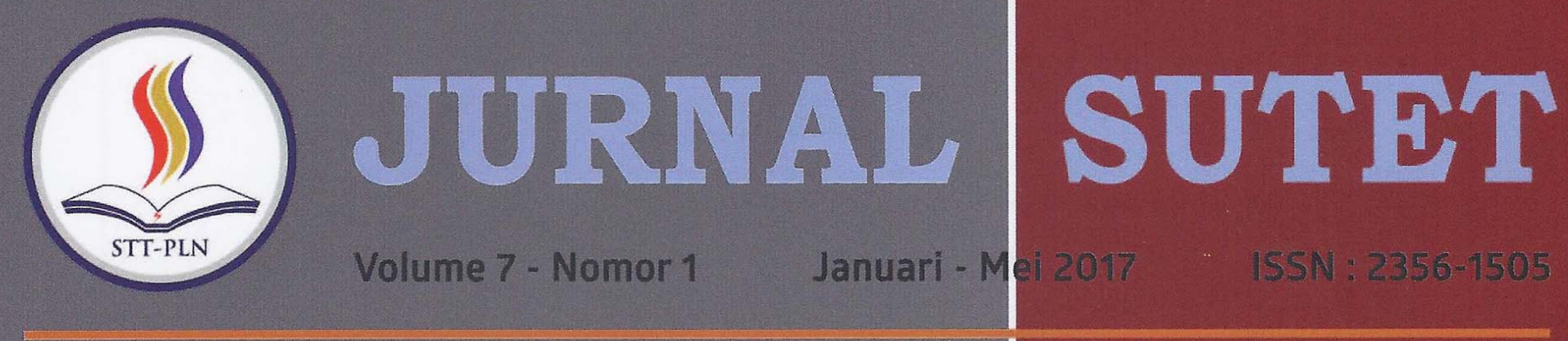

DESAIN SISTEM ALARM MOBIL BERBASIS SMS

Erlina; Hendrianto Husada; Bambang Tri Atmodjo

KELAYAKAN PENGGUNAAN PENDINGIN THERMOELEKTRIK UNTUK PENGHEMATAN DAYA LISTRIK PADA BASE TRANSCEIVER

Sunaryo; Uno Bintang Sudibyo; Supriadi Legino

WITRICITY (WIRELESS ELECTRICITY)

Aas Wasri Hasanah; Oktaria Handayani

CONCEPTUAL DESIGN FOR MITIGATING HARMONIC DISTORTION ON ESP INSTALLATION: CASE STUDY IN KAJI SEMOGA FIELD, MEDCO E\&P INDONESIA

Sandy Suryakusuma; Suprapto Atmowiranto; Dadang Darmawan

RANCANGAN RANGKAIAN ANTI BOUNCING UNTUK RANGKAIAN DIGITAL

Tasdik Darmana

STUDI POWER WHEELING DIKAWASAN INDUSTRI JABABEKA

Bimo Brillianta; Uno Bintang Sudibyo; Wildan Aripin

PEMASANGAN ARRESTER DAN ARCING HORN PADA PENGHANTAR BERISOLASI DI SUTM $20 \mathrm{kV}$ Christine Widyastuti; Andi Makkulau

PENGELOLAAN EMISI GAS LANDFILL (BIOGAS) SEBAGAI ENERGI TERBARUKAN Isworo Pujotomo; Muchamad Nur Qosim

DISAIN SISTEM PENTANAHAN PROTEKSI PETIR SISTEM MULTIPLE VERTICAL ELECTRODES PADA TERMINAL LAWE-LAWE - PERTAMINA DHP

Ibnu Hajar

ANALISA DCS (DISTRIBUTED CONTROL SYSTEM) PADA PROSES POLIMERISASI

Syarif Hidayat; Irsyadi Akbar Jay

PENGEMBANGAN TEKNOLOGI SISTEM SMART MICROGRID DI SEKOLAH TINGGI TEKNIK PLN Heri Suyanto; Agung Hariyanto

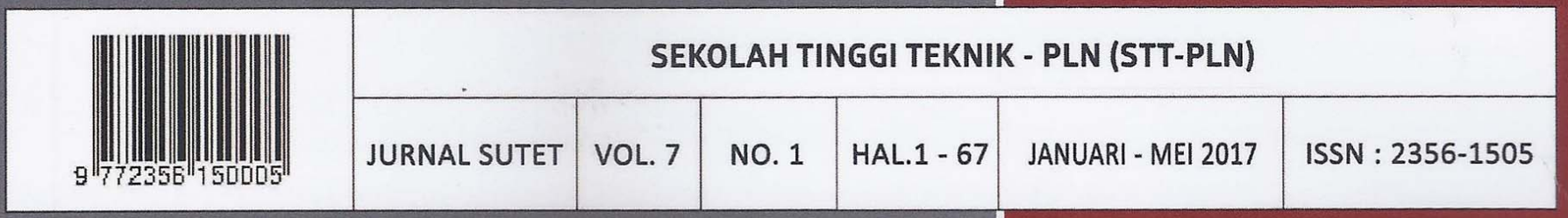




\title{
PEMASANGAN ARRESTER DAN ARCING HORN PADA PENGHANTAR BERISOLASI DI SUTM $20 \mathrm{kV}$
}

\author{
Christine Widyastuti ${ }^{1}$, Andi Makkulau ${ }^{2)}$, \\ Teknik Elektro Sekolah Tinggi Teknik - PLN \\ 1'christinewidyastuti@gmail.com \\ ªndimakkulau@gmail.com
}

\begin{abstract}
Temporary disturbance in medium-voltage air ducts is a disturbance mainly caused by lightning. This disorder is divided into two kinds according to the occurrence of lightning strikes, namely direct strike and indirect strike (induction). This disorder is very difficult to predict, therefore it needs good protection. To protect the equipment from a lightning strike then mounted arresters and arcing horn mounted on a 20kV SUTM network simultaneously. The combination of arresters and arcing horns in medium voltage networks can improve the reliability of the disturbances caused by tighter lightning. Lightning strikes an isolated conductor causing a flashover and causing a disruption to the network, and can damage the conductor, in which case the arrester and arcing horn secure the conductor so as not to break due to the spark jump followed by the current follow-up, in this paper discussed how Arresters and arcing horns installed simultaneously at medium voltage.
\end{abstract}

Key words : Lightning strike trouble, arrester, arcing horn

\begin{abstract}
Abstrak : Dalam proses pendistribusian tenaga listrik, dalam hal ini khususnya saluran tegangan menengah (SUTM), terdapat beberapa masalah yang tidak dapat dihindari,, antara lain adalah gangguan yang disebabkan tegangan lebih petir. Gangguan ini sangat sulit diprediksi, oleh karena itu diperlukan perlindungan yang baik. Untuk melindungi peralatan dari sambaran petir maka dipasang arrester dan arcing horn yang dipasang pada jaringan SUTM 20kV secara bersamaan.Pengkombinasian arrester dan arcing horn di dalam jaringan tegangan menengah dapat meningkatkan keandalan yang cukup baik terhadap gangguan yang diakibatkan oleh tegangan lebih petir. Petir menyambar penghantar berisolasi sehingga mengakibatkan lompatan bunga api (flashover) dan mengakibatkan gangguan pada jaringan, serta dapat merusak konduktor, dalam hal ini arrester dan arcing horn mengamankan konduktor tersebut supaya tidak putus akibat lompatan bunga api yang diikuti arus ikutan, dalam tulisan ini dibahas bagaimana arrester dan arcing horn dipasang bersamaan pada tegangan menengah.
\end{abstract}

Kata kunci : gangguan sambaran petir, arrester, arcing horn

\section{PENDAHULUAN}

Gangguan temporer pada saluran udara tegangan menengah adalah gangguan terutama disebabkan oleh petir. Gangguan ini dibedakan menjadi dua macam menurut terjadinya sambaran petir, yaitu sambaran langsung dan sambaran tidak langsung (induksi). Panjang gawang saluran udara tegangan menengah berkisar antara 40 sampai 80 meter, tetapi pentanahan tiang dilakukan selang 3 sampai 4 gawang, yaitu untuk saluran dengan kawat tanah atau kawat netral. Jadi sambaran langsung dianggap terjadi pada semua tiang, baik pada tiang yang diketanahkan maupun pada tiang yang tidak diketanahkan dengan jumlah sambaran dianggap sama. Untuk saluran udara tegangan menengah, karena ketinggian dan tingkat isolasinya, sambaran induksi mengakibatkan lebih banyak gangguan dari pada sambaran langsung. Pengamanan terhadap saluran udara terhadap tegangan lebih umumnya dilakukan dengan pemasangan arrester. 
Tetapi pemasangannya bersamaan dengan pemasangan arcing horn. Arrester dan arcing horn melindungi peralatan sistem tenaga listrik dengan cara membatasi besarnya tegangan lebih yang datang dengan mengalirkannya ke tanah.

\section{LANDASAN TEORI}

\subsection{Petir}

Medan listrik yang ditimbulkan oleh awan bermuatan pada gambar 1. (a) akan menyebabkan ionisasi udara di sekitarnya. Proses ionisasi udara berkembang terus dan membentuk kanal yang sangat konduktif dengan didahului oleh alur pandu yang diikuti cahaya dan disebut pelopor pelepasan.
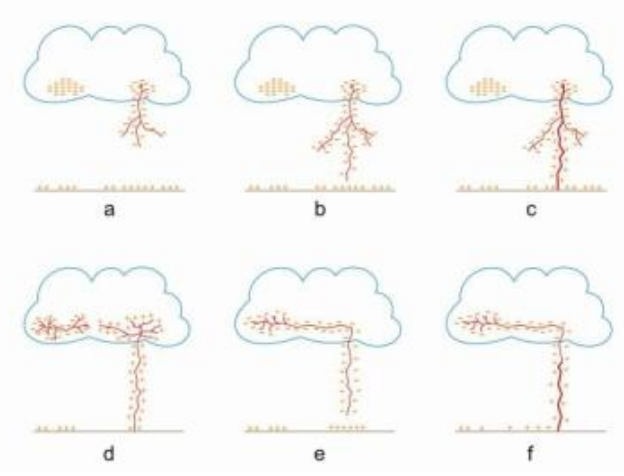

Gambar 1. Proses terjadinya petir

Bentuk gelombang surja petir adalah bentuk gelombang naik dalam waktu singkat dengan penurunan yang lambat (impuls). Dari gambar 2 dapat dilihat gelombang surja petir dengan parameternya, yaitu :

- Muka gelombang (Tf)

Bagian dari gelombang yang dimulai dari titik nol (nominal) sampai titik puncak (menurut IEC ditentukan dari titik nominal perpotongan antara sumbu waktu dengan garis lurus yang menghubungkan $30 \%$ dan $90 \%$ dari tegangan puncak). Besarnya adalah $1,2 \mu \mathrm{s}$.

- $\quad$ Ekor gelombang (Tt)

Bagian dari puncak gelombang sampai turun $50 \%$ dari titik puncak, 50 $\mu \mathrm{s}$.

- Tegangan Puncak (Vs)
Tegangan tertinggi dari awal terjadinya gelombang.

- Kelebihan Tegangan (V')

Timbul di luar tegangan puncak. Pada umumnya kelebihan tegangan ini sebesar $\pm 0,05 \times$ Vs.

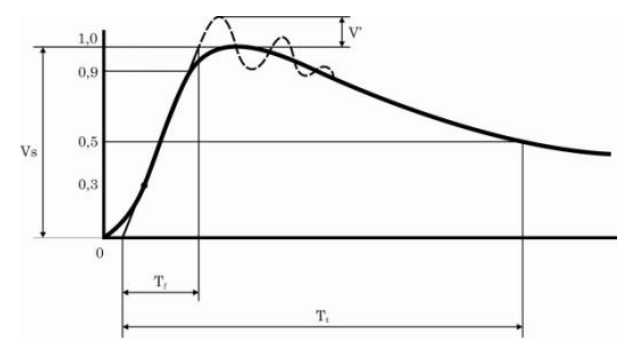

Gambar 2. Bentuk Tegangan Surja Petir

\subsection{Arrester}

Pengamanan peralatan terhadap tegangan lebih petir umumnya menggunakan arrester dan arcing horn. Arrester ini melindungi peralatan sistem tenaga listrik dengan cara membatasi surja yang datang dan mengalirkannya ke tanah. Arcing horn adalah alat pelindung yang paling sederhana. Saat ada gangguan petir, petir itu tidak langsung menghantam konduktor berisolasi melainkan kena arcing horn yang akan menghindari adanya loncatan api, dari arcing horn tersebut petir akan langsung jatuh ke tanah.

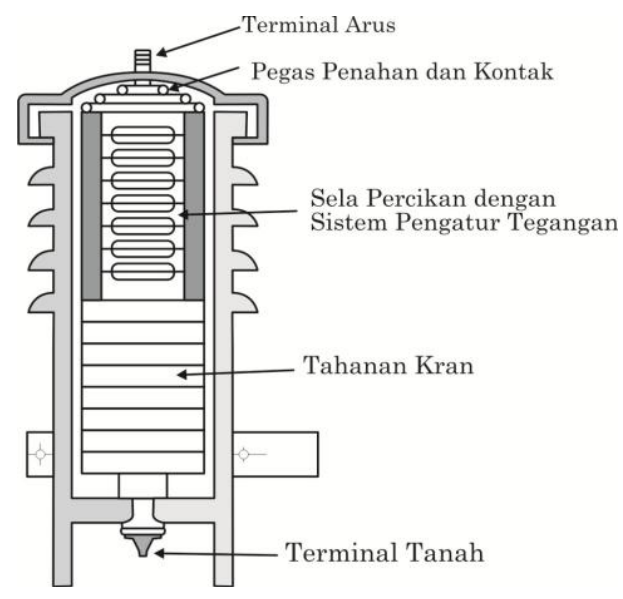

Gambar 3.Konstruksi Dasar Arrester Tahanan Kran

\subsubsection{Jenis Arrester}

\section{a. Arrester Jenis Ekspulsi atau} Tabung Pelindung

Arrester jenis ekspulsi atau tabung pelindung pada prinsipnya terdiri dari sela 
percik yang berada dalam tabung serat dan sela percik batang yang berada di udara atau disebut sela seri.

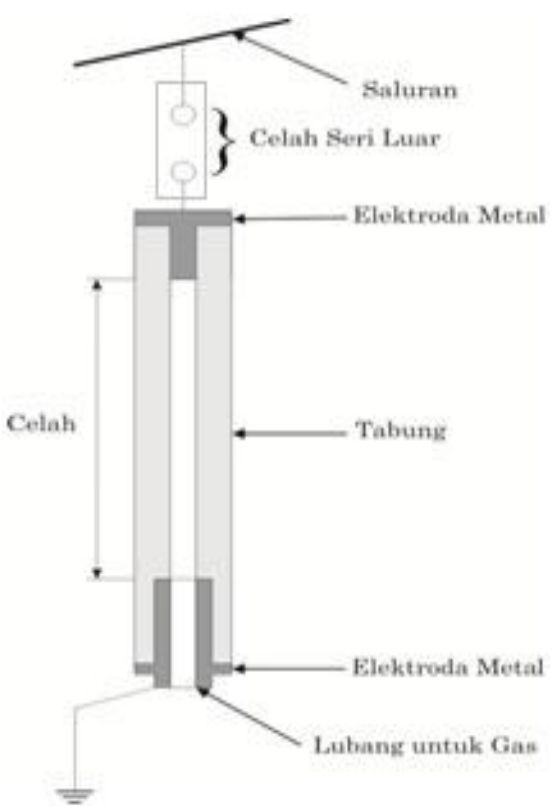

Gambar 4. Elemen-Elemen Arrester Jenis Ekspulsi atau Tabung Pelindung

\section{b. Arrester Jenis Katup}

Arrester Jenis Katup ini terdiri dari sela percik terbagi atau sela seri yang terhubung dengan elemen tahanan yang mempunyai karakteristik non linier. Tegangan frekuensi dasar tidak dapat menimbulkan tembus pada sela seri. Apabila sela seri tembus pada saat tibanya suatu surja yang cukup tinggi, alat tersebut menjadi penghantar.

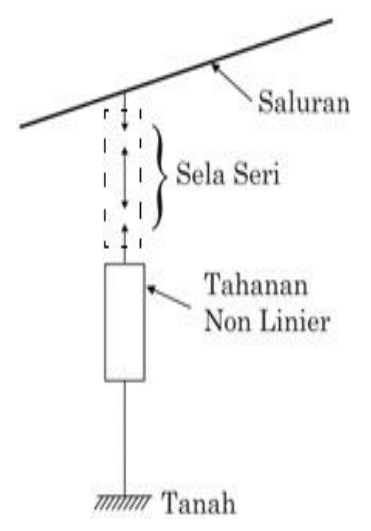

Gambar 3.5. Elemen-Elemen Arrester Jenis Katup

\subsubsection{Arcing Horn}

Arcing horn disebut sebagai tanduk api yang biasanya dipasang pada ujung kawat saluran dan ujung tanah dari isolasi atau groundingnya. Bentuknya sedemikian rupa sehingga busur api yang terjadi pada saat adanya gangguan tidak akan mengenai isolator sewaktu lompatan api itu terjadi.

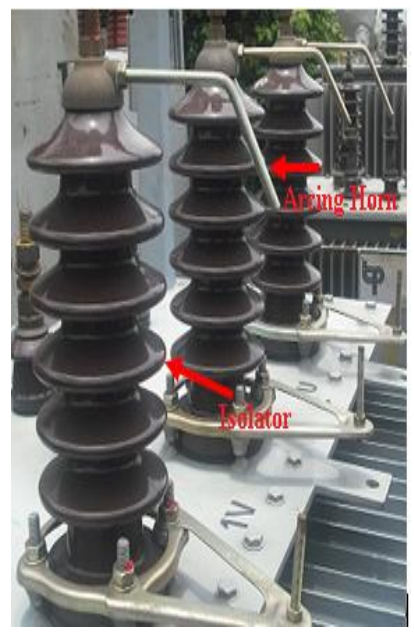

Gambar 6. Arcing Horn di Bushing Trafo

\subsection{Jarak Perlindungan}

2.3.1. Menentukan Jarak antara Arrester dan Alat yang Dilindungi

$$
E p=E a+2 A \frac{s}{v} \ldots . .(1)
$$

2.3.2. Menentukan Jarak Current Limiting Arcing Horn

$$
E p=E a+2 A \frac{2 s}{v}
$$

2.3.3. Karakteristik V-I untuk Memadamkan Api Pada Current limiting Arcing Horn

$$
V t=V r+V g \ldots . .(3)
$$

\section{METODE PENELITIAN}

Jenis penelitian yang dilakukan adalah dengan melakukan percobaan pengkombinasian antara arester dan arcing horn untuk meningkatkan keandalan terhadap sambaran petir dan bagaimana supaya tidak rusak/putus akibat dari adanya lompatan api (flashover) pada konduktor berisolasi di jaringan SUTM 20kV sehingga mempunyai keandalan yang sama apabila terpasang sendiri. 


\section{HASIL DAN PEMBAHASAN}

\subsection{Menentukan Jarak Current Limiting Arcing Horn}

Arrester mempunyai rating :

$>$ Untuk Tegangan : $12 \mathrm{kV}$

$>$ Untuk Arus : $5 \mathrm{kA}$

> Lightning Impulse Sparkover Voltages $(1.2 / 50 \mu \mathrm{s}): 32,6 \mathrm{kV}$

$>$ Tegangan lompatan impuls $50 \%$ pada isolator jenis pin: $160 \mathrm{kV}$

$>$ Kecepatan rambat gelombang: 500 $\mathrm{m} / \mu$ det

$>$ Kecuraman gelombang datang: $300 \mathrm{kV} / \mu$ det

$>$ Tegangan percik arrester (sparkover voltage): $32,6 \mathrm{kV}$

Sehingga :

$160=32,6+2 \times 300 \frac{2 s}{500}$

$160-32,6=2,4 \mathrm{~s}$

$\mathrm{s}=53,083$ meter

Maka untuk 2 jarak current limiting arcing horn adalah:

$\mathrm{CLAH}=2(53,083 \mathrm{~m})=106,166$ meter

Jarak efektif current limiting arcing horn dengan current limiting arcing horn lain sebesar 106,166 meter. Panjang gawang sebesar 50 meter, maka jarak pemasangan current limiting arcing horn dengan current limiting arcing horn lain setiap dua gawang sekali yaitu 100 meter.

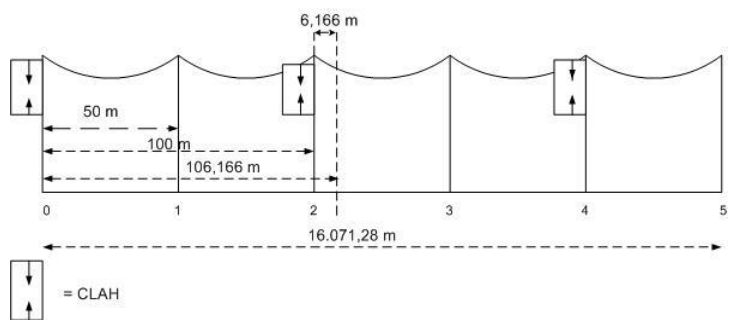

Gambar 7. Jarak efektif pemasangan current limiting arcing horn di penyulang Lampu

\subsection{Karakteristik V-I untuk Memadam- kan Api Pada Current limiting Arcing Horn}

Didapat :

$$
\begin{aligned}
& 160=32,6+V g \\
& 160-32,6=V g \\
& V g=127,4 \mathrm{kV}
\end{aligned}
$$

Tegangan impuls gap sebesar 127,4 $k V$. Sehingga terlihat di dalam grafik gambar 8, didapat besar celah (d) maksimum sebesar $20,5 \mathrm{~cm}$. Semakin kecil jarak besar celah, maka semakin bagus lompatan api dapat dipadamkan dan tidak terjadi backflashover pada peralatan.

Tabel 4.1. Tegangan Percik (Sparkover voltage) untuk rod gaps

\begin{tabular}{|c|c|c|c|}
\hline $\begin{array}{c}\text { Gap } \\
\text { Spacing } \\
(\mathrm{cm})\end{array}$ & $\begin{array}{c}\text { Sparkover } \\
\text { Voltage } \\
(\mathrm{kV})\end{array}$ & $\begin{array}{c}\text { Gap } \\
\text { Spacing } \\
(\mathrm{cm})\end{array}$ & $\begin{array}{c}\text { Sparkover } \\
\text { Voltage } \\
(\mathrm{kV})\end{array}$ \\
\hline 2 & 26 & 30 & 172 \\
\hline 4 & 47 & 40 & 225 \\
\hline 6 & 62 & 50 & 278 \\
\hline 8 & 72 & 60 & 332 \\
\hline 10 & 81 & 70 & 382 \\
\hline 15 & 102 & 80 & 435 \\
\hline 20 & 124 & 90 & 488 \\
\hline 25 & 147 & 100 & 537 \\
\hline
\end{tabular}

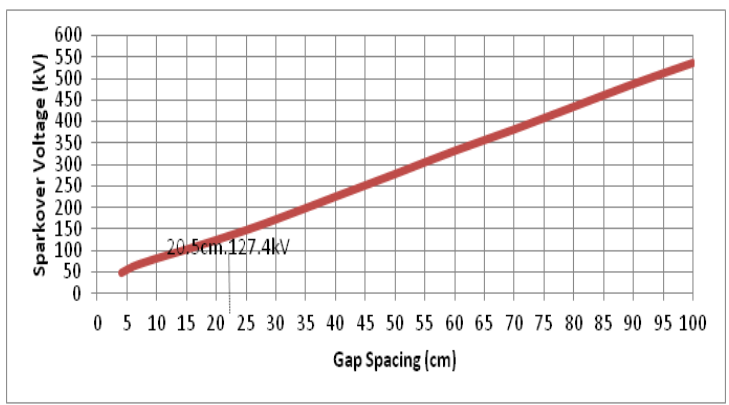

Gambar 8. Hubungan antara gap spacing dengan sparkover voltage untuk rod gap

\section{Struktur Current Limiting Arcing Horn}

Gambar 9 menunjukkan struktur current limiting arcing horn. Ring horn dipasang di sisi atas dari arrester dan pemasangan perangkat keras yang mampu di operasikan ke sisi ujung dari isolator yang disediakan di bagian bawah. Current limiting arcing horn saat ini dapat dengan mudah di operasikan ke saluran yang ada, tanpa menyentuh bagian energi. Hal ini dimungkinkan untuk melakukan instalasi bahkan di bawah kondisi udara yang panas. Karena adanya kesenjangan udara, semua tegangan AC tidak diterapkan pada arrester, sehingga menghilangkan kerusakan elemen. Unsur ini tidak akan menyebabkan kerusakan pada tanah bahkan hal buruk sekalipun. 
- $\quad$ Current Limiting Element (Arrester) Tahanan $\mathrm{ZnO}$ nominal pelepasan arus 2500 A digunakan untuk penangkap petir. Arrester yang dibentuk oleh karet EPT (Ethylen Propylene Tertiary polymer) yang ketahanan cuacanya bagus, tahan air, dan tahan cahaya.

\section{- $\quad$ Ring Horn}

Ring horn terbuat dari stainless steel dan membentuk cincin. Cincin tersusun secara langsung agar lompatan api berkisar pada pengosongan, berlawanan dengan kecuraman gelombang petir.

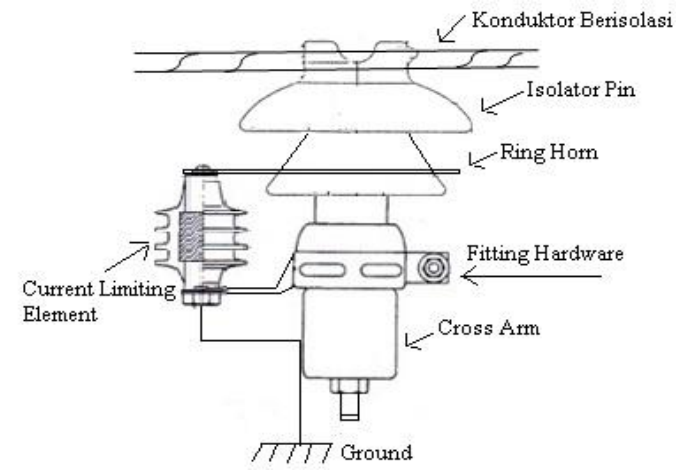

Gambar 9. Struktur Current Limiting Arcing Horn

\section{KESIMPULAN}

a Current limiting arcing horn telah dikembangkan untuk mencegah konduktor terbakar/meleleh dan gangguan sementara pasokan listrik karena petir. Current limiting arcing horn memiliki tahanan nonlinier $\mathrm{ZnO}$ yang berfungsi memadamkan api (arc) dan pemulihan cepat dari isolasi.

b Jarak efektif current limiting arcing horn dengan current limiting arcing horn lain di jaringan sebesar 106,166 $\mathrm{m}$ (untuk 2 jarak). Panjang gawang adalah 50 meter, sehingga pemasangan current limiting arcing horn setiap dua gawang sekali sejarak 100 meter.

c Current limiting arcing horn mempunyai besar celah (gap spacing) sebesar $20,5 \mathrm{~cm}$. Semakin kecil nilai celah semakin bagus lompatan api dapat dipadamkan dan tidak terjadi backflashover pada peralatan.

\section{REFERENSI}

Arismunandar, Artono dan S. Kuwahara, 2004,Buku Pegangan Teknik Tenaga Listrik Jilid III Gardu Induk, P.T. Pradnya Paramita,Jakarta.

Arismunandar, Artono, 1984, Teknik Tegangan Tinggi, P.T. Pradnya Paramita ,Jakarta

Basri, Hasan, 1997,Sistem Distribusi Daya Listrik, ISTN Jakarta

STANDAR PERUSAHAAN LISTRIK NEGARA, 1978,SPLN 7, Pedoman Pemilihan Tingkat Isolasi Transformator dan Penangkap Petir.

M. Washino, A. Fukuyama, K. Kito, K. Kato. (1988). IEEE Transactions on Power Delivery, Vol.3, No.1, Januari "Development Of Current Limiting Arcing Horn For Prevention Of Lightning Faults On Distribution Lines". 